\title{
DIE THEORIEN
}

\section{DER \\ ELEKTRODYNAMIK}

NACH IHRER GESCHICHTLICHEN ENTWICKELUNG.

\author{
VoN
}

\section{DR. GEORG HELM,}

GEH. HOFRAT,

O. PROFESBOR AN DER K. TECHNISCHEN HOCHSCHULE ZU DRESDEN.

\section{MIT FIGUREN.}

\section{LEIPZIG}

VERLAG VON VEIT \& COMP. 
Druck von Metzger \& Wittig in Leipzig 